\title{
MIDAS
}

Museus e estudos interdisciplinares

$8 \mid 2017$

Dossier temático "Objetos e museus: biografias, narrativas e vínculos identitários"

\section{Os cómodos do Museu Casa de Rui Barbosa enquanto museália}

The rooms of the House Museum of Rui Barbosa as museum objects

\section{Aparecida Marina de Souza Rangel e Álea Santos de Almeida}

\section{(2) OpenEdition}

\section{Journals}

\section{Edição electrónica}

URL: http://journals.openedition.org/midas/1300

DOI: $10.4000 /$ midas. 1300

ISSN: 2182-9543

\section{Editora:}

Alice Semedo, Paulo Simões Rodrigues, Pedro Casaleiro, Raquel Henriques da Silva, Ana Carvalho

\section{Refêrencia eletrónica}

Aparecida Marina de Souza Rangel e Álea Santos de Almeida, «Os cómodos do Museu Casa de Rui Barbosa enquanto museália », MIDAS [Online], 8 | 2017, posto online no dia 31 julho 2017, consultado no dia 01 maio 2019. URL : http://journals.openedition.org/midas/1300 ; DOI : 10.4000/midas.1300

Este documento foi criado de forma automática no dia 1 Maio 2019.

\section{cc) (†)}

Midas is licensed under a Creative Commons Attribution-NonCommercial-ShareAlike 3.0 International License 


\section{Os cómodos do Museu Casa de Rui Barbosa enquanto museália}

The rooms of the House Museum of Rui Barbosa as museum objects

Aparecida Marina de Souza Rangel e Álea Santos de Almeida

\section{NOTA DO EDITOR}

Artigo recebido a 30.03.2017

Aprovado para publicação a 28.06.2017

\section{Introdução}

1 Nas casas-museu desenvolve-se uma poética específica, surgida do diálogo entre o privado e o público, presente em diversas dimensões discursivas que perpassam os objetos, o personagem e a sua residência. Na sua forma mais clássica, a casa-museu é um espaço que guarda as marcas físicas e simbólicas da sua origem, que são presentificadas e ressignificadas não só pelo processo de reconstrução da memória provocado pelos discursos expositivos, mas também pelo olhar do visitante.

Entre as muitas possibilidades de entendimento deste espaço e dos vieses analíticos que perpassam a dialética entre o privado e o público, está em questão não somente a musealização de objetos móveis, mas também da casa e dos seus cómodos que são, ao mesmo tempo, conteúdo e espaço que abriga a museália (ou objetos de museu) e da sua própria história. As conexões entre estas instâncias são viscerais e, portanto, fundamentais na teoria relacional que caracteriza esta tipologia de museu. Nesta perspetiva, procuramos compreender os cómodos do Museu Casa de Rui Barbosa, na cidade do Rio de Janeiro (Brasil) como objetos de museu passíveis, portanto, de 
cumprirem toda a logística que compõe a musealização: preservação, pesquisa, documentação e comunicação.

3 Na primeira parte do artigo, considerando um entendimento dos cómodos enquanto museália, analisamos a estrutura geral do Museu Casa de Rui Barbosa, caracterizando cada cómodo ou espaço. A casa, de estilo neoclássico, possui cerca de 25 ambientes dispostos numa construção semelhante a um sobrado com planta em forma de U (corpo principal), articulada com um corpo lateral e jardim. Cada cómodo possui, além da sua conformação na residência, uma trajetória específica num contexto mais amplo, retratando as mudanças dos hábitos e costumes da sociedade, sobretudo a partir da ocupação espacial. A casa que se tornou sede da instituição serviu de residência para Rui Barbosa e sua família entre 1893 e 1923, configurando-se como o cenário privilegiado de diversos acontecimentos da vida privada e pública do seu patrono.

4 Na segunda parte do artigo refletimos sobre o papel dos cómodos enquanto museália e as respetivas implicações para a Museologia. Neste contexto, analisamos as conceções de património e de objeto de museu que desafiam as abordagens mais tradicionais de museália.

5 A investigação desenvolvida insere-se no campo da Museologia, mas dialoga com áreas afins, quer pelo seu contexto histórico e social, quer pela necessidade de abordar as suas categorias conceituais à luz de autores que investigam temas ligados às casas-museu. A metodologia seguida atendeu à pesquisa bibliográfica sobre esta Casa-Museu e o seu sistema de inventário e catalogação, incluindo uma revisão de literatura quanto ao modelo concetual das casas-museu. Neste artigo apresentam-se os resultados parciais de um projeto de investigação mais alargado intitulado "Desenvolvimento de Metodologia para Catalogação dos Ambientes de um Museu-casa, Compreendidos como Objetos Museológicos" desenvolvida no âmbito do "Programa de Incentivo à Produção do Conhecimento Técnico e Científico na Área da Cultura da Fundação Casa de Rui Barbosa". ${ }^{1}$

\section{Os cómodos do Museu Casa de Rui Barbosa}

6 Museu é um verbete, uma palavra, um lugar, aparentemente simples se o definirmos no seu aspeto denotativo. Todavia, simbolicamente encontramos uma teia de significados envolvendo esta categoria social, e como tal, em permanente fluxo com o meio externo. Desde a década de 1970, o termo museu vem sofrendo um alargamento concetual para se adequar às transformações sociais, demonstrando o seu caráter processual. Este metamorfismo atípico marcado por mudanças conceituais sem, contudo, alterar a essência do termo que tem na sua interface com a memória o seu eixo central, incentivou cientistas sociais de diferentes campos do conhecimento a eleger o museu como objeto de estudo. Para melhor compreensão e análise das diferentes características, os museus são agrupados em modelos conceituais: museus de ciência, museus de arte, museus de história, ecomuseus, entre outros. Numa única categoria - "museu" - encontramos diferentes processos de construção de memória e práticas culturais. Entre os modelos conceituais que definem os museus, a casa-museu é provavelmente o que apresenta os questionamentos mais desafiantes, sobretudo por estarmos a trabalhar com duas categorias conceituais complexas: casa e museu. Embora aparentemente distintas, estas categorias permitem aproximações e reflexões que caminham na mesma direção. Quando uma casa é musealizada e, tendo esta sido habitada por um morador ilustre, em geral, pretende-se que o seu patrono seja o viés das relações sociais e interpretativas que são 
estabelecidas. Contudo, a dimensão da casa sobrepõe-se, muitas vezes, ao biográfico, e residência e personagem confundem-se. A casa, afirmou Gilberto Freyre, «é museu quando esta ultrapassa os tempos, é o lugar da memória porque nela o homem brasileiro encontra as suas origens e é patrimônio porque nela reside a voz de um passado por ela testemunhado» (cit. por Ribeiro 2006, 58).

7 No caso do Museu Casa de Rui Barbosa trata-se da musealização da residência de um personagem ilustre da política e história brasileira. A casa que se localiza na Rua São Clemente, 134, no bairro de Botafogo, no Rio de Janeiro, serviu de residência do jurista Rui Barbosa e sua família entre 1893 e 1924, tendo sido transformada em casa-museu em 1927. Personagem polémico, Rui Barbosa nasceu em Salvador a 5 de novembro de 1849 e desde muito cedo se destacou pela sua capacidade intelectual. Considerado um dos maiores oradores do seu tempo, ainda hoje é lembrado pelos seus discursos rebuscados e longos.

8 A atuação de Rui Barbosa em campos tão variados da política e da cultura brasileira - foi advogado, jornalista e político -, deixou um legado importante. Atuando e escrevendo em diversas frentes, Rui Barbosa refletiu sobre a educação no Brasil, a separação da Igreja e do Estado, e a importância do direito internacional, entre outras questões. Assim, a trajetória da casa está entrelaçada com a biografia do jurista. É também importante lembrar que esta história não se iniciou com a transformação da residência em museu. A partir do momento em que a mesma foi adquirida, em 1893, pelo então Senador Rui Barbosa, esta passou a ser testemunho edificado da vida pública e privada deste personagem.

9 A residência não foi ocupada pela família de imediato. $O$ ano da sua compra é marcado por um momento político bastante conturbado na vida de Rui Barbosa que culminou com o seu exílio em Inglaterra, onde se estabeleceu com a família até 1895, ano em que retornou ao Brasil.

O casarão foi construído em 1850 por Bernardo Casimiro de Freitas, Barão da Lagoa, em terreno que, antes do loteamento, fazia parte da fazenda do padre Clemente Martins. Anos mais tarde a propriedade foi vendida ao comendador português Albino de Oliveira Guimarães que, em 1890, a vendeu ao inglês John Roscoe Allen. Rui Barbosa foi, então, o quarto proprietário da casa que, em homenagem à sua esposa, recebeu o nome de Vila Maria Augusta.

11 Durante o tempo em que Rui Barbosa e a sua família residiram na casa foram feitas várias melhorias como a instalação de água canalizada (quente e fria), a substituição do sistema de iluminação da casa, que antes era feita através do gás domiciliar, e passou a ser feita através de luz elétrica, e a instalação de um telefone. Estas melhorias são testemunhos das inovações neste contexto histórico (Fundação Casa de Rui Barbosa 2000), ressaltando, ainda, que a casa também contava com duas casas de banho, algo pouco comum nas casas brasileiras deste período (Rangel 2015). 


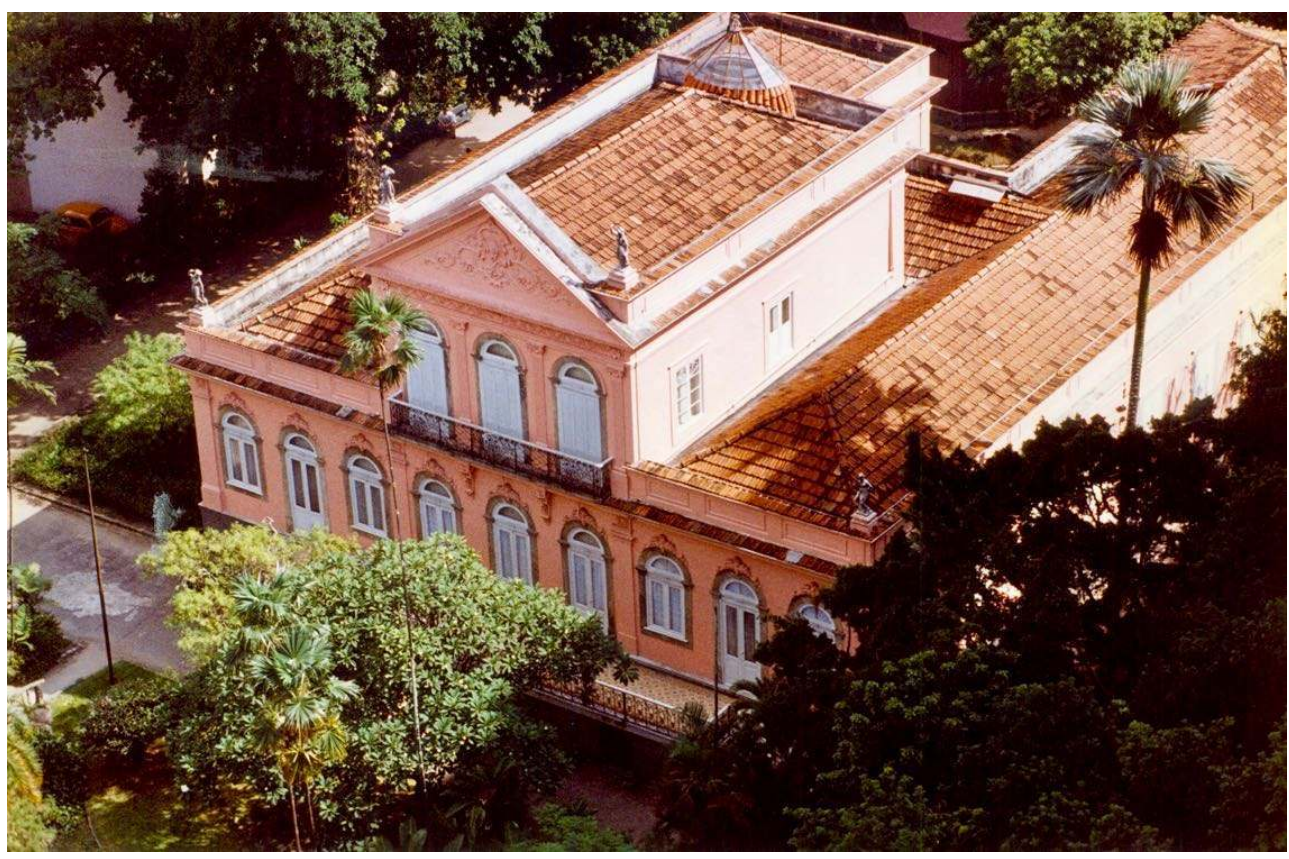

Fig. 1 - Vista aérea da casa onde viveu Rui Barbosa, 1995, Museu Casa de Rui Barbosa Fotografia de Rogério Reis ( ) Arquivo da Fundação Casa de Rui Barbosa

A casa é um exemplar do estilo neoclássico brasileiro. No andar térreo existe um porão, onde se localiza uma das entradas da casa (atual receção do Museu Casa de Rui Barbosa) e, separados do corpo principal da residência, existem alguns cómodos que tiveram diferentes utilizações ao longo do tempo e que atualmente abrigam a biblioteca infantojuvenil Maria Mazzetti e a administração do Museu.

13 No primeiro piso da residência, os ambientes reservados à privacidade são separados do espaço social através de um grande corredor. Entre os cómodos privados encontram-se o quarto de Maria Luiza Vitória (que era chamada pela família de Baby), a filha mais nova de Rui Barbosa, o quarto do casal, o quarto de vestir de D. Maria Augusta, esposa de Rui Barbosa, e uma casa de banho. Onde anteriormente era o quarto de Baby reproduz-se atualmente o escritório de Rui Barbosa da sua casa de veraneio, em Petrópolis, apelidado por ele de "gabinete holandês" devido aos móveis que foram adquiridos na Holanda (Fundação casa de Rui Barbosa 2000). 0 corredor dá acesso às três salas de receção: sala de visitas, salão de baile e sala de música, que se conectam com o exterior. Estas salas também comunicam com os espaços destinados aos estudos de Rui Barbosa, um escritório chamado por este de "gabinete gótico", em função da decoração superior das estantes e a biblioteca, o maior cómodo da casa, que atualmente expõe no seu local original mais de 37 000 livros que faziam parte da biblioteca particular do patrono, motivo de orgulho e distinção social (Rangel 2015).

Ao lado da biblioteca fica o quarto de vestir de Rui Barbosa, com armário que contém roupas e objetos pessoais do intelectual, havendo ainda um biombo usado para ocultar um vaso sanitário portátil. $O$ cómodo ao lado é um gabinete de trabalho que conta com uma grande mesa utilizada por ele para a redação do seu famoso e polémico parecer, quando Rui Barbosa era senador e relator da Comissão Especial do Senado do projeto do Código Civil (Fundação Casa de Rui Barbosa 2000).

15 Ainda no primeiro piso, ao fundo, nas áreas destinadas ao convívio mais íntimo, encontrase uma pequena sala de estar, com paredes pintadas no estilo pompeano, onde a família se 
reunia com os amigos e onde a esposa de Rui Barbosa, Maria Augusta, recebia as amigas para o chá. Ao lado está a sala de jantar, onde se comemoravam os aniversários e se recebiam os convidados especiais. Seguindo em frente, há a sala de almoço, onde a família fazia as refeições quotidianas, geralmente na presença de amigos íntimos. A área destinada aos serviços e empregados inicia-se com a copa (que fica ao lado da sala de almoço), seguida de uma casa de banho, despensa (atualmente ocupada pelo LACAM Laboratório de Conservação de Acervo Museológico), quarto das crianças e das suas babás (onde está exposta a cama onde Rui Barbosa faleceu), refeitório dos empregados (área destinada à reserva técnica do Museu) e cozinha (Fundação Casa de Rui Barbosa 2000).

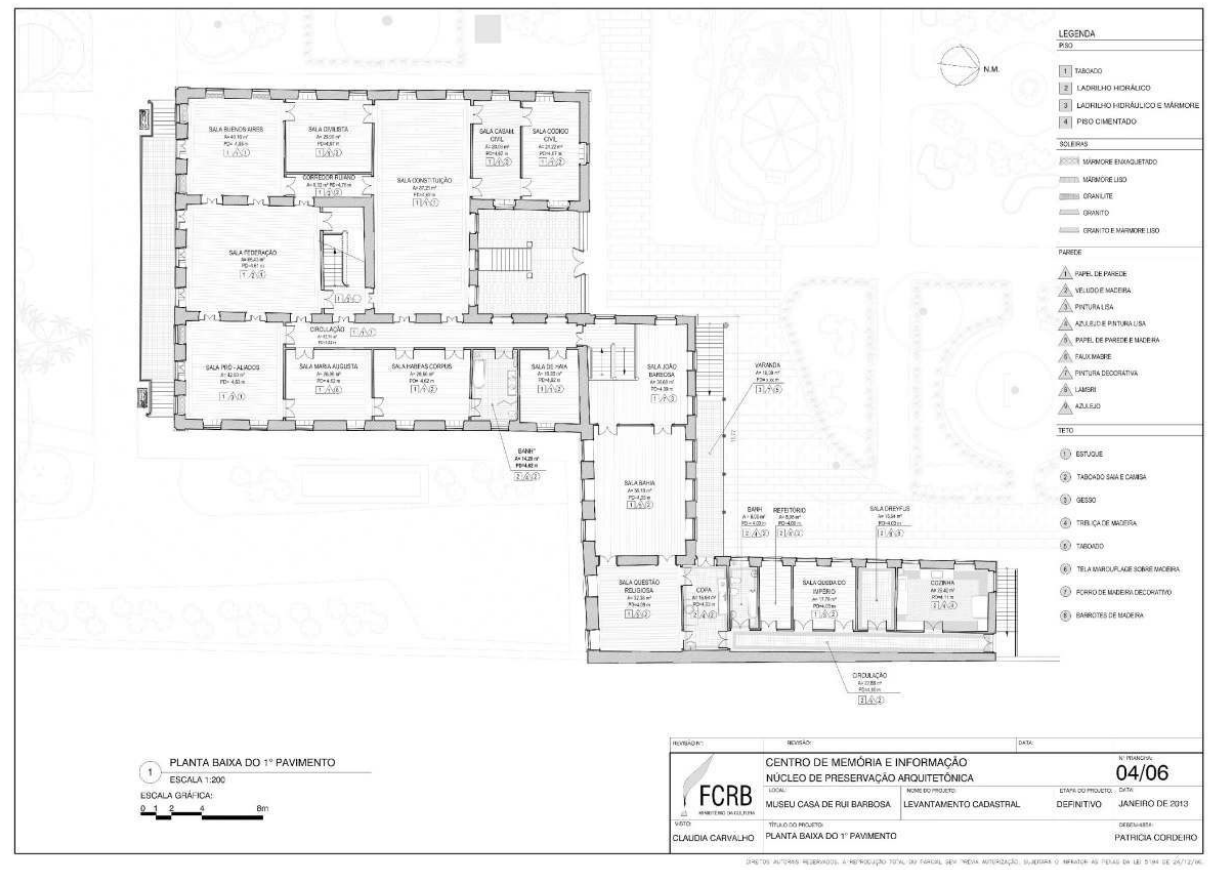

Fig. 2 - Planta baixa do primeiro piso da casa, janeiro de 2013, Museu Casa de Rui Barbosa Desenho de Patrícia Cordeiro (c) Fundação Casa de Rui Barbosa 


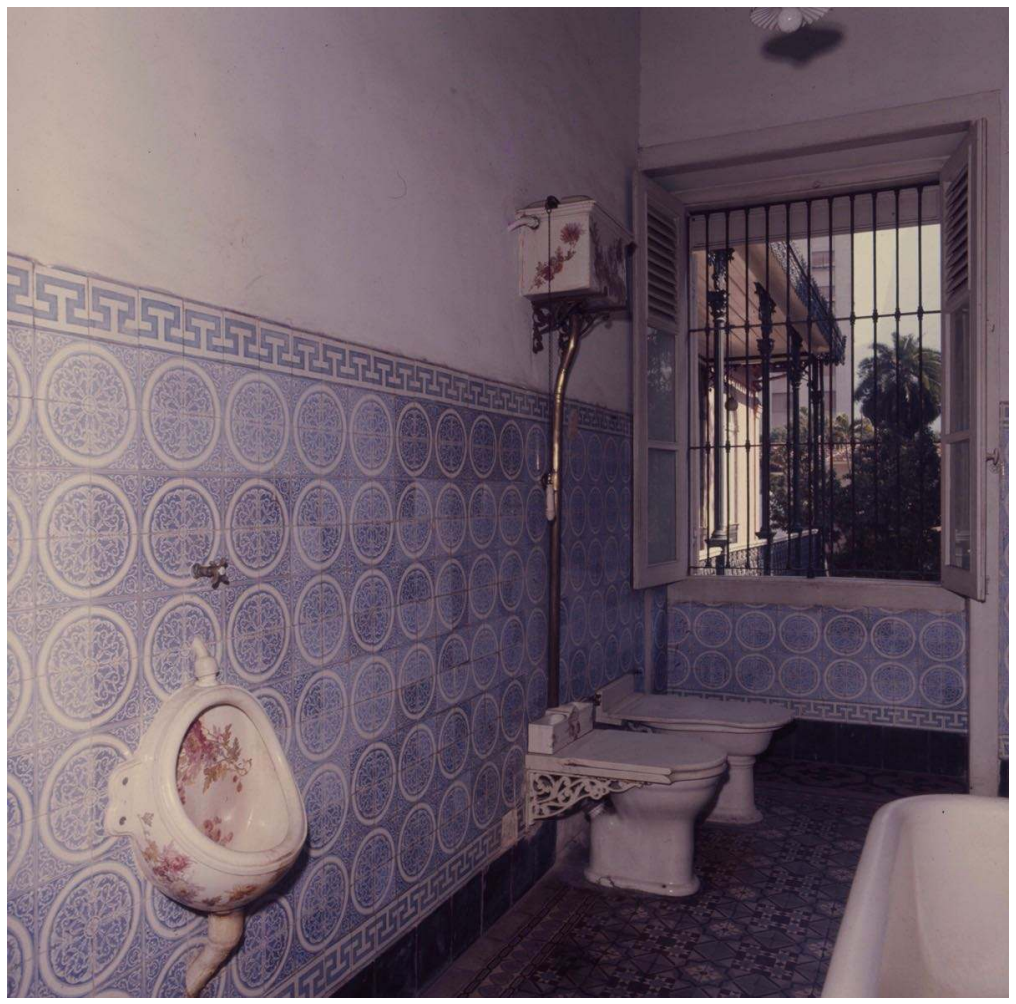

Fig. 3 - Casa de banho junto à copa, 1974-1977, Museu Casa de Rui Barbosa Fotografia de Marcel Gautherot (c) Arquivo da Fundação Casa de Rui Barbosa

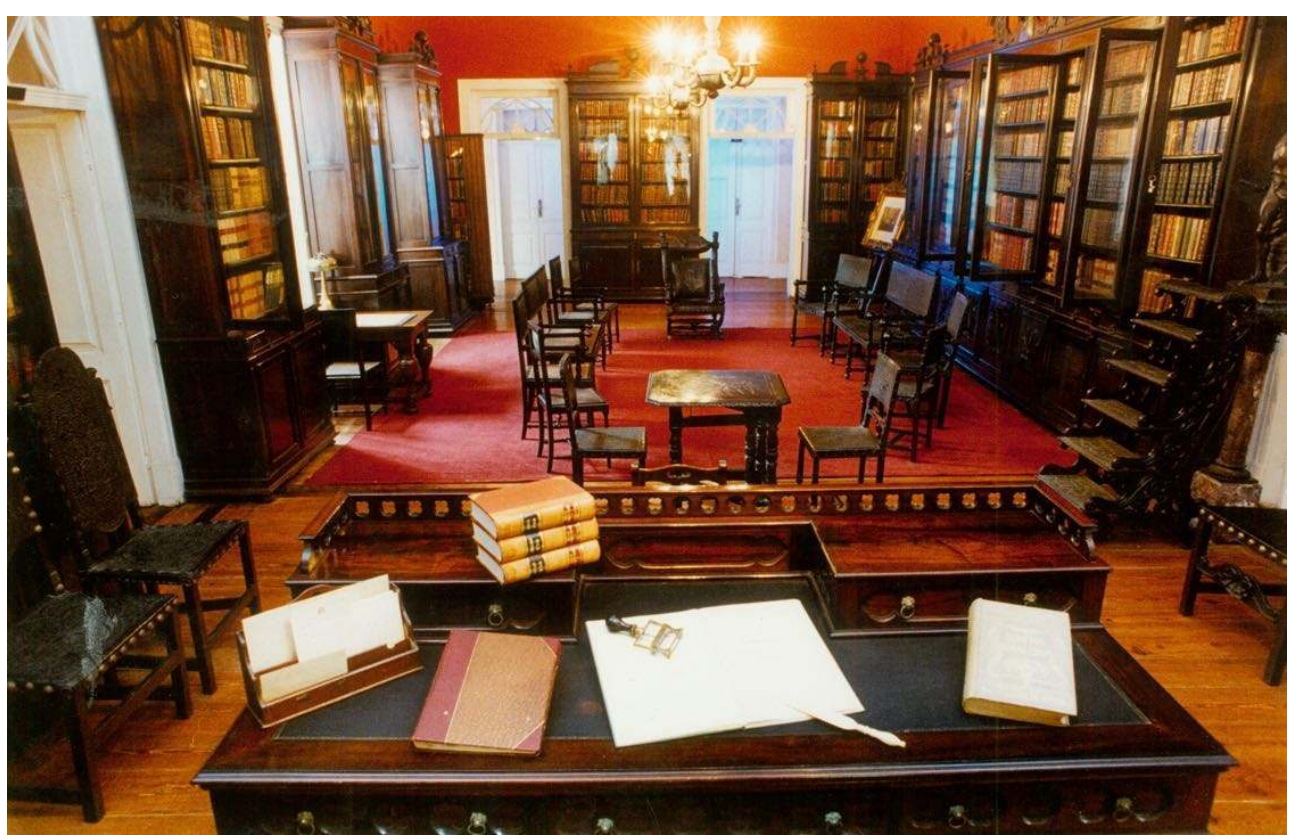

Fig. 4 - Sala Constituição (biblioteca), 1995, Museu Casa de Rui Barbosa Fotografia de Rogério Reis (c) Arquivo da Fundação Casa de Rui Barbosa

O sobrado abrigava inicialmente o quarto dos filhos de Rui Barbosa, mas posteriormente os cómodos foram ocupados pela filha mais velha de Rui Barbosa, Maria Adélia, e pelo seu marido, Antônio Batista Pereira. No quarto da frente dormia o casal, no quarto ao lado as crianças, e uma pequena sala liga os dois aposentos. Nestes cómodos, a mobília original já 
não existe e atualmente são expostos móveis da casa da família de Petrópolis (Fundação Casa de Rui Barbosa 2017).

Desde a inauguração da casa-museu em 1930, cada divisão recebeu um nome, fazendo referência a três aspetos da vida de Rui Barbosa: o político, o jurista e o familiar. Os cómodos com as denominações alusivas à vida política foram a Sala de Haia ("gabinete holandês"), Sala Pró-Aliados (sala de visitas); a Sala Federação (salão de baile), a Sala Buenos Aires (sala de música), a Sala Civilista ("gabinete gótico", o pequeno escritório onde Rui Barbosa trabalhava), a Sala Constituição (biblioteca), a Sala Abolição (no sobrado, quarto da filha mais velha de Rui Barbosa, Maria Adélia, e do seu marido Antônio Batista Pereira), a Instrução Pública (quarto dos filhos de Maria Adélia), o Estado de Sítio (saleta no sobrado), a Queda do Império (quarto da babá e das crianças, no primeiro pavimento), e a Questão Religiosa (sala de almoço). Os cómodos que fazem referência à trajetória de Rui Barbosa como jurista são as salas: Habeas Corpus (quarto do casal), Casamento Civil (quarto de vestir de Rui Barbosa) e Código Civil (gabinete de trabalho), e a sala que era o refeitório dos empregados (atual reserva técnica) recebeu o nome de Dreyfus. As salas que lembram os aspetos familiares receberam as seguintes designações: João Barbosa (sala de estar com paredes pintadas no estilo pompeano), Pai de Rui Barbosa; Maria Augusta (quarto de vestir da esposa de Rui Barbosa) e Bahia (sala de jantar), local de nascimento do intelectual.

Em geral, a decoração da casa é requintada e preserva a distinção social da família, com pinturas murais, quadros, tapetes, porcelanas, bronzes decorativos (muitos destes objetos são homenagens que Rui Barbosa recebeu pela sua atuação em diferentes atividades); e com teto decorado em estuque (Rangel 2015). Uma boa parte da mobília e muitos objetos foram importados, o que revela a influência europeia no gosto de Rui Barbosa, que se encarregava pessoalmente da decoração da casa. Aos objetos trazidos de viagens, juntavam-se também aqueles comprados em lojas famosas da época, tais como a Mappin \& Webb, Casa Leonardo e Loja América e China (Fundação Casa de Rui Barbosa 2000).

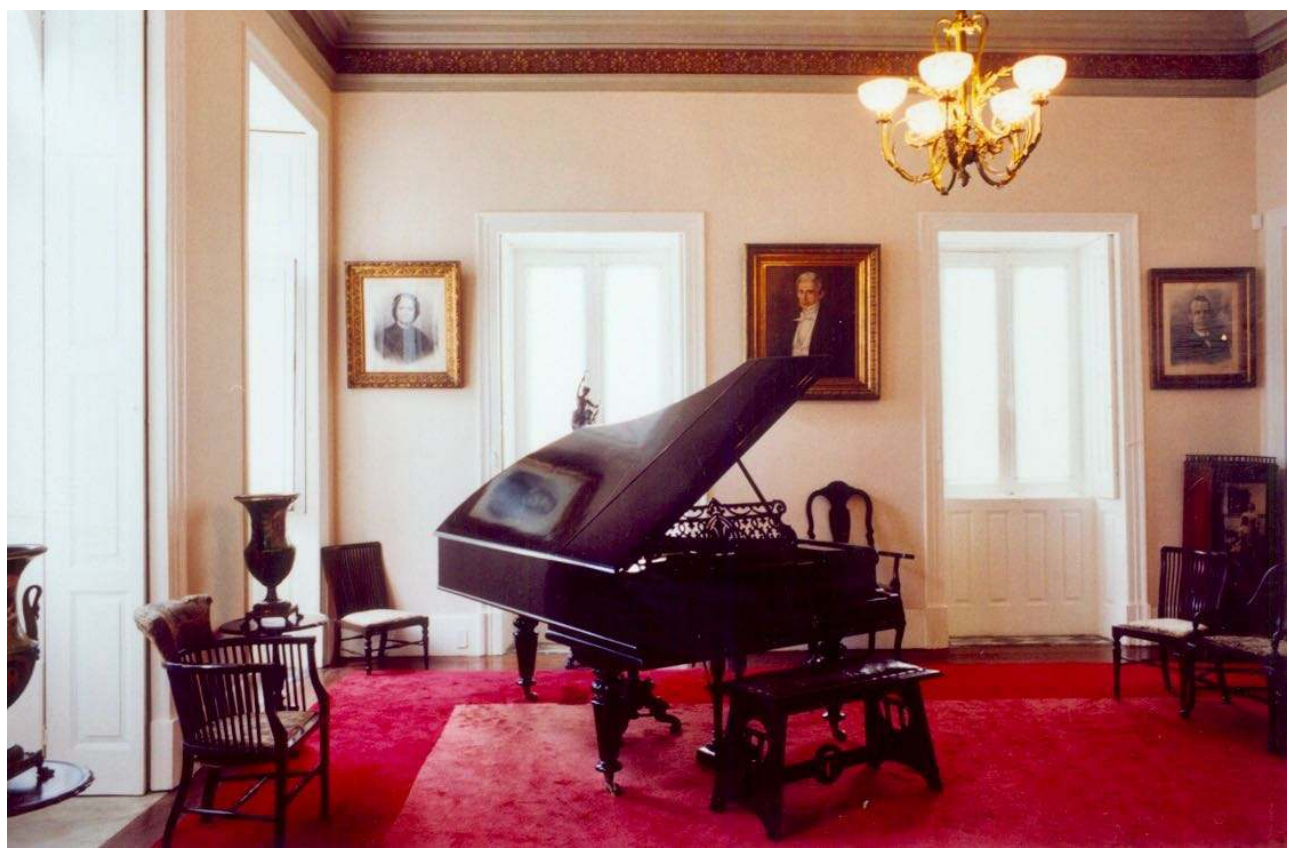

Fig. 5 - Sala Buenos Aires (sala de música), data não determinada, Museu Casa de Rui Barbosa Fotografia de autor não identificado (c) Arquivo da Fundação Casa de Rui Barbosa 
Rui Barbosa e a sua família viveram 28 anos na casa. Após a morte do intelectual em 1923, houve uma grande comoção pública que culminou na musealização da residência, que abriu ao público em 1930. A partir de 1966 alterou-se a personalidade jurídica da instituição, sendo transformada em Fundação Casa de Rui Barbosa. O Museu Casa de Rui Barbosa, atualmente uma divisão que integra o Centro de Memória e Informação da Fundação Casa Rui de Barbosa, tem atuado no sentido de reunir muitos dos objetos que foram dispersos após a morte do patrono. Durante a década de 1960, a instituição já havia conseguido reunir grande parte do acervo atual, cujos critérios de aquisição foram baseados na relação direta do objeto com o personagem ou com a sua família, contabilizando aproximadamente 1550 objetos de diferentes categorias que incluem mobiliário, porcelana, prataria, indumentária, viaturas, entre outras. Esta origem influenciou a organização das categorias de classificação dos objetos do acervo: no Livro A constam os objetos pertencentes a Rui Barbosa, esposa e filhos; o número de registro de cada objeto é formado por esta letra, o ano em que a peça foi registrada no Museu (esta data pode ou não coincidir com o ano da sua entrada na instituição); sendo o livro B subdividido em quatro categorias: coleção Família de Rui; coleção Reconstituição de Ambientes; coleção Relacionados a Rui; coleção Objetos Diversos (Rangel 2015).

Esta breve caracterização dos cómodos do Museu Casa de Rui Barbosa demonstra como estes ambientes tiveram uma trajetória social que se entrelaça com a biografia de Rui Barbosa, sendo também testemunhos de um período histórico. Esta premissa foi a principal motivação para iniciarmos no final de 2016 o projeto "Desenvolvimento de Metodologia para Catalogação dos Ambientes de um Museu-casa, Compreendidos como objetos Museológicos" que pretende realizar um levantamento, por amostragem, da documentação existente em algumas casas-museu dispersas pelo país, bem como propor a construção de uma ferramenta específica para o registro dos ambientes deste modelo concetual.

O entendimento e registro da trajetória social da casa passa pela pesquisa do percurso dos cómodos, unidades menores que nos permitem compreender a profundidade da conexão entre objetos móveis e os seus ambientes. A casa de banho, o quarto, a sala e todos os outros cómodos de uma casa-museu são também documentos com carga simbólica e materialidade, sendo imprescindível a sua catalogação e pesquisa como qualquer objecto museológico.

\section{Os cómodos-objetos do Museu Casa de Rui Barbosa: espaços físicos e conceituais}

22 A catalogação de objetos móveis é um procedimento conhecido nos museus brasileiros, como nos apontam os dados da publicação Museus em Números (IBRAM 2011) baseada no Cadastro Nacional de Museus, realizado pelo Instituto Brasileiro de Museus, em 2010. Segundo a mesma publicação os principais instrumentos utilizados pelos museus para o registro do seu acervo são: livro de registro (44,5 \%); ficha de catalogação (42,6 \%); documentação fotográfica $(34,7 \%)$ e softwares de catalogação $(26,1 \%)$. Ainda que $26,3 \%$ das instituições que participaram no estudo em questão ${ }^{2}$ tenham informado não possuir nenhum instrumento de registro do acervo, verifica-se um consenso geral de que tal prática é fundamental para a preservação e disseminação do conhecimento. A 
inexistência de registro compromete as funções básicas de um museu, pois a preservação, a investigação e a comunicação são processos encadeados e indissociáveis.

Para compreendermos os objetos de museu (ou museália) podemos começar por investigar a sua criação, ou seja, o momento em que um objeto tem o seu estatuto alterado por meio de um processo de musealização. Encontramos processo análogo em reflexões na área da filosofia, na transformação da coisa em objeto; através desta comparação poderemos compreender o principal dispositivo da transformação de um objeto quotidiano em museália. Heidegger (1987) explica que a coisa estabelece uma relação de continuidade com o sujeito, é algo que faz parte do quotidiano numa espécie de simbiose com o indivíduo. Pode ser uma pedra, uma folha, uma mesa, um assunto, enfim, tudo o que nos cerca. Já com o objeto o que ocorre é que este se funde justamente na separação com o sujeito, ou seja, o objeto é aquilo que o sujeito coloca diante de si e torna diferente de si. Sendo assim, diferentemente do que ocorre com a coisa, não há aqui nenhuma relação de continuidade, mas sim de separação - relação que define tanto o sujeito quanto o objeto.

24 Na musealização encontramos uma proposta semelhante, o objeto do quotidiano que tem funções utilitárias pode, em alguns casos, ser musealizado e separado do sujeito e da vida quotidiana, passando a ter função de testemunho de uma cultura ou sociedade. A musealização é um processo complexo que envolve ações de preservação, documentação, investigação e comunicação feitas sobre e a partir dos objetos de museu. A operação que se destaca é a que se refere à comunicação do objeto, pois é nesse momento que os profissionais colocam os objetos diante do público, criando um discurso.

Também é importante notar que o entendimento do que é o objeto de museu e no que consiste o processo de musealização sofreram modificações ao longo do tempo. Brulon (2015) observa que a musealização enquadra os objetos em sistemas classificatórios específicos que, ao longo do tempo, se modificam e, consequentemente, também o seu entendimento enquanto museália. Até ao início do século $\mathrm{XX}$, a noção de museália restringia-se aos objetos móveis que durante a musealização se enquadravam em sistemas classificatórios vinculados a disciplinas científicas. Porém, a partir da segunda metade do século XX surgiram questionamentos quanto à conceção tradicional de património, o que implicou uma reflexão mais ampla de museália - admitindo-se que o conceito de objeto de museu é abarcado pela noção mais abrangente de património. Para Desvallées (2015), tais indagações tiveram entre as suas causas o surgimento dos ecomuseus e dos museus comunitários em França durante a década de 1970. Estas novas tipologias de museu passaram a lidar com as conceções antropológicas do património, redimensionando as fronteiras deste conceito, envolvendo elementos destituídos até então de valores patrimoniais e simbólicos.

O surgimento destes modelos concetuais de museu abriu caminho para uma mudança importante que possibilitou repensar a noção de objeto de museu e a inserção das comunidades nos processos de construção das suas próprias narrativas. Estes são objetos que fazem parte da vida quotidiana e que durante muito tempo foram negligenciados pelos museus tradicionais, que operavam com os conceitos do excecional, belo e autêntico (Desvallées 1987). Tal operação ocorreu porque houve uma mudança no rumo da missão dos museus, que passaram a privilegiar as relações que se estabelecem com a comunidade e o território a nível local, gerando um redimensionamento semântico do termo. 0 próprio termo musealização transcende o processo de transformação da coisa em objeto 
de museu, podendo referir-se à transformação de um lugar, um edifício ou de um sítio natural em museu (Desvallées e Mairesse 2013).

As diferentes conceções de museália encontram ressonância nas casas-museu, sobretudo porque, como defendemos, nestes espaços a casa, as suas divisões, os objetos e a personagem estão ligados. A preservação, quando restrita aos objetos móveis utilizados pelos antigos moradores da casa, inibe o potencial discursivo deste modelo concetual tão rico em possibilidades de leitura e abordagens críticas. Desta forma, na casa-museu os cómodos têm grande importância, pois estes (e as relações estabelecidas entre esses espaços) são testemunhos de como uma família vivia, se a sua vida social era agitada ou não (existência de muitos ambientes sociais), se era uma família abastada (existência ou não de área de serviço para muitos empregados), se era a casa de um letrado (existência e tamanho da biblioteca), entre outros aspetos. Também é importante sublinhar que os cómodos não são testemunhos apenas da rotina familiar, mas também das suas relações com o mundo exterior, retratando, assim, os hábitos, os costumes e o modo de viver de um determinado período.

Tratando especificamente a estrutura e a trajetória da casa onde hoje é o Museu Casa de Rui Barbosa, Rangel (2015) relaciona a casa da família de Rui Barbosa com um contexto maior de transformações no espaço da casa, reflexo das mudanças ocorridas nas esferas públicas e privadas a partir dos séculos XVII e XVIII. Partindo das reflexões de Habermas (2003), a autora explica que durante esses séculos, o salão de convivência de natureza pública vai aos poucos dando lugar à sala de estar da pequena-família. Assim, surge a sala de receção na casa da família, em que as pessoas da esfera privada se reúnem em público. A linha entre a esfera pública e a esfera privada é física e passa pelo meio da casa, com separação clara entre as seções da mesma. As pessoas saem da intimidade dos quartos para o espaço público do salão. A investigadora continua a sua argumentação observando que a casa da família de Rui Barbosa segue a seguinte organização: os quartos estão separados do espaço social através de um grande corredor que dá acesso às três salas de receção (sala de visitas, salão de baile e sala de música). Estas salas estão ligadas aos espaços destinados aos estudos de Rui Barbosa, incluindo a biblioteca, que também podem ser isolados através do fechamento das portas de folhas duplas. Dessa forma, a casa é dividida em núcleos com funções específicas, demonstrando a separação entre a parte social e pública, e a parte íntima, separação que não é natural, mas sim construída ao longo dos séculos, refletindo mudanças culturais e sociais.

29 Esta tessitura permite compreender a importância que os cómodos de uma casa-museu têm no processo de construção discursiva, corroborando a necessidade de os musealizar, tal como é feito com os bens móveis que integram o acervo museológico. As informações referentes aos cómodos, a sua trajetória histórico-social, dimensões, medidas relacionadas com a sua conservação, enfim todos os campos que compõem uma ficha de inventário podem fazer parte do registro deste cómodo-objeto que passará a ser compreendido como fonte de produção de conhecimento. Muitos caminhos e produtos são vislumbrados a partir do desenvolvimento deste estudo que contempla entre outros aspetos, a investigação sobre o ambiente doméstico no Brasil e as suas relações com as esferas pública e privada.

Voltando à questão da museália e do seu alargamento concetual, reforça-se a necessidade de registrar a sua trajetória histórico-social, além dos aspetos físicos já tradicionalmente incorporados. Os objetos circulam por diversos meios sociais e culturais, estabelecendo relações com diferentes sujeitos, entrando e saindo de regimes de valor e de classificação. 
Depois de dar início ao processo de musealização, a vida social dos objetos continua, pois estes permanecem sendo ressignificados, estabelecendo novas relações e interpretações.

Para estudar as trajetórias dos objetos antes e depois da musealização, podemos apoiarnos em pesquisas do campo da antropologia, mais especificamente as que se ocupam das questões relacionadas com a circulação de mercadorias. A partir dessas pesquisas podemos refletir sobre as trajetórias sociais dos objetos antes da sua transformação em museália e, simultaneamente, compreender que estes objetos continuam "vivendo" após o processo de musealização com um regime de valor próprio do espaço museal. Appadurai (2008) argumenta que as mercadorias possuem vida social, já que os objetos são valorizados e ganham significados durante as trocas estabelecidas durante a sua trajetória. Dessa forma, durante a sua vida social, os objetos emergem em diferentes regimes de valor e vão adquirindo significado. Para que possamos compreendê-los é preciso segui-los, pois os seus significados estão inscritos nas suas formas, usos e trajetórias (Appadurai 2008).

Kopytoff (2008) propõe uma análise biográfica dos objetos pelo viés concetual adotado pela antropologia. Para explorar diferentes facetas dos objetos deveríamos indagá-los como fazemos com as pessoas. As biografias são feitas a partir de conceções prévias acerca do que deve ser focalizado, podendo ter uma perspetiva económica, técnica, social, etc. Todas as biografias podem ou não ser culturalmente informadas. Esse tipo de biografia encara o objeto como algo socialmente construído, dotado de significados culturais, classificado e reclassificado em categorias culturalmente constituídas.

Apesar de apresentarem perspetivas diferentes, tanto Appadurai como Kopytoff demonstram que o estudo da biografia ou vida social das mercadorias pode dizer muito sobre os contextos por onde esses objetos circularam. Os valores desses objetos são atribuídos pelos indivíduos durantes as diversas trocas e negociações da sua trajetória. As conceções dos dois autores podem apoiar a construção de uma metodologia para o estudo de "novos" objetos museológicos - os cómodos do Museu Casa de Rui Barbosa. De Appadurai (2008) podemos inferir a importância das trocas, ou seja, das passagens, pois assim como o autor se concentra nas trocas económicas e simbólicas que envolvem as mercadorias, podemos pensar nas mudanças simbólicas que os cómodos da casa-museu passaram ao longo do tempo.

34 Atentemos, como ponto de análise, ao cómodo intitulado como Sala de Haia, que originalmente havia sido o quarto da filha mais nova de Rui Barbosa, Maria Luísa Vitória. Atualmente este cómodo reproduz um escritório de Rui Barbosa que na realidade ficava na casa de veraneio da família, em Petrópolis. Assim, podemos concentrar a nossa pesquisa no entendimento dos momentos de mudanças: de cómodo da filha mais nova (antes da musealização) para escritório de Rui Barbosa (após a musealização), investigando os principais aspetos e componentes do cómodo nestes diferentes momentos e a justificação para as escolhas da expografia pela reprodução do escritório de Petrópolis.

Da conceção de biografia cultural das coisas de Kopytoff (2008), é importante reter a ideia de que o processo de pesquisa deve ser conduzido por perguntas direcionadas aos objetos museológicos. Desta forma, a ficha catalográfica dos cómodos do Museu Casa de Rui Barbosa poderá beneficiar deste princípio, adotando campos que possam direcionar as questões das trajetórias sociais dos cómodos. A construção desta biografia será contínua, já que o início do processo de musealização não interrompe a vida social da muséalia, tendo em mente que a mudança de estatuto faz parte do seu percurso. Desta forma, podemos equacionar cada cómodo da casa-museu (museália) como um objeto adjetivado 
pelo devir, ou seja, um objeto que passou por diferentes estados e exerce funções variadas ao longo da sua trajetória, inclusivamente após a sua entrada no museu. Nesta conceção o que se tem em conta são as relações sociais e conjunturas culturais pelas quais o objeto de museu passa, em constante devir (Brulon 2015).

O objeto privilegiado deste estudo, os cómodos-objetos do Museu Casa de Rui Barbosa, tiveram uma vida social e continuam a ter uma trajetória com um estatuto diferente da sua função original. Durante a sua vida social, estes cómodos-objetos presenciaram festas, reuniões políticas, estudos, refeições, conversas, enfim, uma série de acontecimentos que constroem a memória do patrono e do seu tempo, passando por um processo de transformação após a morte do patrono.

Assim, ressaltamos que nas casas-museu a relação entre o conteúdo e o espaço que abriga a museália configura-se como premissa estrutural, ou seja, o acervo de bens móveis e o lugar onde este se abriga possuem uma conexão; não apenas os objetos deveriam ser registrados segundo os parâmetros museológicos, mas também, numa escala hierárquica equitativa, os ambientes. $\mathrm{O}$ quarto de banho, o quarto, a sala e todos os outros cómodos de uma casa-museu possuem uma representatividade, uma trajetória, além de outros dados que podem ser registrados e receber o mesmo tratamento documental que é geralmente dedicado aos objetos móveis. Da sua construção para abrigar a família do então Barão da Lagoa, passando pela residência do jurista Rui Barbosa, até aos nossos dias como Museu Casa de Rui Barbosa, as mudanças ocorridas nesta casa foram incontáveis, mesmo quando nos restringimos aos aspetos físicos. A casa foi ampliada na sua constituição estrutural, mas também e sobretudo na sua dimensão concetual. Quando Bachelard afirma que «a casa é o nosso canto do mundo» (Bachelard 1993, 24) não o faz de forma aleatória; a associação ao termo "mundo" enfatiza a complexidade contida neste espaço. A casa é o lugar privilegiado da vida privada, onde o sujeito está resguardado das intempéries da vida pública, ainda que estas esferas se interpenetrem.

A análise da história e trajetória da casa, antes de ser museu e depois como museu, revela o quanto os espaços e as personagens vão sendo reelaborados em função do contexto histórico e social em que se inserem. A casa e o museu coabitam e representam metonimicamente a personagem e os fatos que a esta se relacionam.

\section{Considerações finais}

Neste artigo procurámos demonstrar que numa casa-museu como a de Rui Barbosa, conteúdo e espaço que abriga a museália estão entrelaçados. Casa e personagem foram musealizados e tornaram-se fontes de investigação igualmente importantes. Os seus cómodos-objetos são unidades da casa que contêm, cada um com uma trajetória social específica e, além disso, estabelecem com os objetos móveis ali dispostos conexões sociais e culturais que deveriam ser registradas e estudadas. É neste sentido que entendemos cada espaço da casa-museu como museália, ou seja, como testemunho de um período histórico que diz respeito não somente a Rui Barbosa e à sua família, mas também ao contexto social brasileiro de um período que, por sua vez, dialoga com outros encadeamentos históricos, geográficos e sociais. Este entendimento implica um alargamento do conceito de museália, inserindo-o em discussões que questionam a noção mais convencional de objeto de museu. 
Apesar de ser um projeto ainda em andamento, é possível inferir que a metodologia de inventariação dos cómodos da casa-museu pode ser uma proposta inovadora no contexto da investigação em museus-casas em termos nacionais como internacionais. Esta abordagem, que considera a casa, os cómodos e do que pode ser a museália nas casasmuseu poderá contribuir para o aprofundamento da área de documentação museológica nestas instituições, produzindo novos conhecimentos, possibilidades de pesquisa e outros olhares.

\section{BIBLIOGRAFIA}

Appadurai, Arjun. 2008. “Introdução: Mercadorias e a Política de Valor.” In A vida Social das Coisas, ed. Arjun Appadurai, 15-88. Niterói: Editora da Universidade Federal Fluminense.

Bachelard, Gastón. 1993. A Poética do Espaço. São Paulo: Martins Fontes.

Brulon, Bruno. 2015. "Os Objetos de Museu, entre a Classificação e o Devir.” Informação \& Sociedade: Estudos 25 (1): 25-37.

Desvallés, André, e François Mairesse. 2013. Conceitos-chave de Museologia. São Paulo: Comitê Brasileiro do Conselho Internacional de Museus/Secretaria de Estado da Cultura.

Desvallés, André. 2015. “Uma Virada da Museologia.” In Anais do Museu Histórico Nacional (MHN) 47: 69-85.

Fundação Casa de Rui Barbosa. 2000. Museu Casa de Rui Barbosa: Guia do Visitante. Rio de Janeiro: Casa de Rui Barbosa.

Habermas, Jürgen. 2003. Mudança Estrutural da Esfera Pública: Investigações Quanto a uma Categoria da Sociedade Burguesa. Rio de Janeiro: Tempo Brasileiro.

Heidegger, Martin. 1987. Que é uma Coisa? Doutrina de Kant dos Princípios Transcendentais. Tradução de Carlos Morujão. Lisboa: Edições 70.

IBRAM. 2011. Museus em Números. vol. 1. Brasília: Instituto Brasileiro de Museus.

IBRAM. 2011.Guia dos Museus Brasileiros. Brasília: Instituto Brasileiro de Museus.

Kopytoff, Igor. 2008. “A Biografia Cultural das Coisas: A Mercantilização como Processo.” In A Vida Social das Coisas, ed. Arjun Appadurai, 89-121. Niterói: Editora da Universidade Federal Fluminense.

Rangel, Aparecida Marina de Souza. 2015. "Museu Casa de Rui Barbosa: Entre o Público e o privado." Tese de doutorado, Universidade do Estado do Rio de Janeiro.

Ribeiro, Rodrigo Alves. 2006. “Moradas da Memória: A Construção de um Museu na Casa de Gilberto Freyre." Dissertação de mestrado, Universidade Federal do Ceará. 


\section{NOTAS}

1. Neste projeto foram ainda aplicados questionários a profissionais de museus de várias casasmuseu e analisaram-se as fichas catalográficas das mesmas.

2. Vale a pena ressaltar que o Cadastro Nacional de Museus mapeou 3025 museus, mas somente 1 500 responderam ao questionário enviado. Os dados foram divulgados, entre outros instrumentos, em duas publicações: o Guia Brasileiro de Museus (2011) e o Museus em Números (2011), ambos editados pelo Instituto Brasileiro de Museus.

\section{RESUMOS}

Este artigo apresenta os resultados parciais do projeto de investigação "Desenvolvimento de Metodologia para Catalogação dos Ambientes de um Museu-casa, Compreendidos como Objetos Museológicos", desenvolvida no âmbito do "Programa de Incentivo à Produção do Conhecimento Técnico e Científico na Área da Cultura da Fundação Casa de Rui Barbosa". Este estudo, em desenvolvimento, procura compreender os cómodos do Museu Casa de Rui Barbosa (Rio de Janeiro, Brasil) como objetos de museu - museália -, com o objetivo de desenvolver uma metodologia de pesquisa e de inventário destes ambientes. Para o entendimento dos cómodos enquanto museália procurámos caracterizá-los brevemente, demonstrando a importância destes ambientes na trajetória da casa-museu dedicada a Rui Barbosa (1849-1923) e o seu valor enquanto testemunhos de um contexto histórico e social. Reflectimos também sobre a conceção de cómodo enquanto museália e as implicações desta abordagem para o campo da Museologia. A metodologia de investigação seguida atendeu a uma revisão de literatura quanto ao modelo concetual das casas-museu, a uma pesquisa bibliográfica sobre esta Casa-Museu e sobre inventariação e documentação museológica. Sendo o entendimento do cómodo da casa-museu enquanto museália algo novo no contexto desta tipologia de museu, esta abordagem poderá contribuir para o aprofundamento da documentação museológica em casas-museu.

This article presents partial results of the research project "Development of a Methodology for Cataloguing the Environments of a Museum-house, Understood as Museum objects", developed within the scope of the "Program of Incentive to the Production of Technical and Scientific Knowledge in the Cultural Area of the Casa de Rui Foundation Barbosa". This study, still under development, seeks to understand the rooms of Museu Casa de Rui Barbosa (Rio de Janeiro, Brazil) as museum objects with the ultimate goal of developing a methodology for researching, inventorying and documenting these environments. In order to understand the rooms as museum objects, firstly we characterize them briefly to demonstrate the importance of these environments in the trajectory of the house of the patron Rui Barbosa (1849-1923), and its value as testimonies of a historical and social context. We also discuss the notion of the rooms as museum objects and the implications of this understanding in the field of Museology. The research methodology relies on literature review about the conceptual model of house museums, bibliographical research about the Museu Casa de Rui Barbosa, and inventory and museum documentation. At this phase, the research conducted demonstrates the relevance of perceiving the house museum rooms as museum objects, a new framework in the context of this typology of 
museum. We argue that this approach can contribute to expand the study of museum documentation in house museums.

\section{ÍNDICE}

Palavras-chave: casa-museu, museália, documentação, Museu Casa de Rui Barbosa, musealização, inventário

Keywords: house museum, musealia, museum object, museum documentation, musealisation, inventory

\section{AUTORES}

\section{APARECIDA MARINA DE SOUZA RANGEL}

Doutora em Ciências Sociais (2015) pelo programa de pós-graduação em Ciências Sociais da Universidade do Estado do Rio de Janeiro (UERJ), mestre em Memória Social e Documento (2001) e bacharel em Museologia (1995), ambos os títulos obtidos na Universidade Federal do Estado do Rio de Janeiro. É desde 2002 Museóloga da Fundação Casa de Rui Barbosa/MinC e docente no programa de pós-graduação em Memória e Acervos, da mesma instituição. Integra os grupos de pesquisa "Arte, Cultura e Poder" da UERJ; e "Perspetivas Conceituais, Memória e Preservação em Museus-Casas" da Fundação Casa de Rui Barbosa, sob sua coordenação. Tem como áreas de interesse: Museologia, casas-museu, memória, educação, avaliação e estudo de públicos. Fundação Casa de Rui Barbosa, Museu Casa de Rui Barbosa, Rua São Clemente, 134, 22.260-000 Rio de Janeiro, Brasil, cida@rb.gov.br

\section{ÁLEA SANTOS DE ALMEIDA}

Mestre em Museologia e Patrimônio pela Universidade Federal do Estado do Rio de Janeiro (UNIRIO). Atua na área da documentação museológica, com experiência em pesquisa e catalogação de acervos. Trabalhou no Museu da Imagem e do Som, no website Museu Virtual de Instrumentos Musicais e no Museu do Samba. Atualmente é bolseira do projeto "Desenvolvimento de Metodologia para Catalogação dos Ambientes de um Museu-casa, Compreendidos como Objetos Museológicos", orientado por Aparecida Rangel e desenvolvido no âmbito do Programa de Incentivo à Produção do Conhecimento Técnico e Científico na Área da Cultura da Fundação Casa de Rui Barbosa.

Fundação Casa de Rui Barbosa, Museu Casa de Rui Barbosa, Rua São Clemente, 134, 22.260-000 Rio de Janeiro, Brasil, aalmeida@hotmail.com 